\title{
Opinions and Understandings of Science Center Visitors About Exhibits and Labels
}

\author{
Canan Laçin-Şimşek* \\ Sakarya University, Education Faculty, Mathematics and Science Education Department, \\ Sakarya, Turkey, ORCID: https://orcid.org/0000-0001-9050-1842
}

\section{Meltem Öztürk}

ORCID: https://orcid.org/0000-0002-1544-8479

\begin{tabular}{ll}
\hline \hline Article history & In this study, it is aimed to determine the opinions and \\
Received: & understandings of the visitors coming to the science center, which \\
15.06 .2020 & is an informal learning environment, about the exhibits and \\
Received in revised form: & labels. For this purpose, the opinions of the visitors about the \\
27.08 .2020 & exhibits and labels, their understanding of the exhibits and labels \\
Accepted: & were examined. The research is qualitatively oriented. The data \\
29.08 .2020 & were collected through semi-structured interviews. The study \\
Key words: & group of the research consists of 95 people visiting Kocaeli \\
\hline $\begin{array}{l}\text { Science Center, } \\
\text { Science Center Visitors, } \\
\text { Informal Learning, }\end{array}$ & $\begin{array}{l}\text { Science Center between October 2017 and December 2018. In the } \\
\text { Exhibit, } \\
\text { Exhibit Labels }\end{array}$ \\
thatysis of the data, content analysis was used. It was determined \\
generally noticed the labels and read them. These visitors stated \\
that the labels should be more colorful, remarkable, more easily \\
understandable, their fonts should be bigger and the narration of \\
the label could be supported with visual elements. The vast \\
majority of the visitors stated that they understood what was told \\
in the exhibit, but when asked what they understood, it was seen \\
that the majority of them did not understood it, some of them \\
only described how to use the exhibit. It is thought that the \\
findings will contribute to the literature regarding the science \\
centers.
\end{tabular}

\section{Introduction}

Science centers, which are among the informal learning environments, are institutions that try to bring together science with society, to make science understandable, and to present scientific facts, principles and laws in a fun and engaging way. In science centers, the hands on and minds on approach is considered important, visitors are expected to touch the exhibits, examine and express ideas on their observations.

\footnotetext{
*Correspondency: csimsek@ sakarya.edu.tr
} 
People have the opportunity to do and see many things in a short time at the science center. There are no time limits for interactive exhibits at the science center, and visitors can continue exploring the exhibits as long as their concentration continues (Caulton, 1998). These discoveries contribute to science center visitors in cognitive, affective and psychomotor domains (Wellington, 1990). Contributions to the cognitive domain can take two forms: first, by providing visitors with direct information; the second is indirectly, leaving positive memories as a result of a process. Contributions to the affective domain through interactive exhibits and experiments; is to enable visitors to be excited, their interest and motivation to increase. In the psychomotor domain, participatory activities contribute to the development of visitors' hand skills and hand-eye coordination. This improves the psychomotor domain. In response to visitors' actions, interactive exhibits invite visitors to more actions and cause more interaction (Eshach, 2007).

It is expected that learning in these environments will be high as visitors visit science centers in accordance with their interests and wishes (Falk and Dierking, 1997) and interact with exhibits. However, in many studies, it has been stated that learning does not occur as expected in science centers (Allen, 2004; Gilbert \& Stocklmayer, 2001; Guisasola, Morentin \& Zuza, 2005; Gutwill \& Allen, 2009; Hakverdi Can, 2013; Falk \& Dierking, 2016; McManus 1990; Ramey-Gassert, 1997; Rennie \& Williams, 2006). The reasons for expected learning is not realized in science centers are that the visitors do not examine the exhibits in depth and their inquiry skills are insufficient (Gutwill \& Allen, 2009), the visitors in the young age group do not read the labelslthe labels are not suitable for their age levels (Hakverdi Can, 2013), prior and posterior experiences influencing visitors' learning in science centers (Falk \& Dierking, 2016), short visit time and visitors often not giving their priority to learning (Gilbert \& Stocklmayer, 2001; Rennie \& Williams, 2006), not making visits associated with lessons (Guisasola, Morentin \& Zuza, 2005; Ramey-Gassert, 1997), visitors give up the study due to the difficulties they experience while using the exhibits (Yaşar \& Gürel, 2014).

While designing exhibits in science centers, it is given importance to explain facts, principles and concepts in a clear and understandable way, and it is aimed to have as much interaction as possible between the exhibit and the visitor (Allen, 2004). Applied and interactive exhibits invite visitors to explore the exhibits more directly, at the same time to touch and/or manipulate exhibit objects (Caulton, 1998). For better understanding of the exhibits in a science center, there are labels with information about how to use the target item, what to observe there or what to look out for. These labels are very important for carrying out correct type of observations and making sense of them. The exhibit can be understood more easily through labels (Hohenstein \& Tran, 2007). So it is important to determine if quality of the labels meet the expectation.

With the popularization of science centers, the question "Are visitors really learning or just playing?" is frequently mentioned (Caulton, 1998). At this point, it is wondered how much the exhibits are understood and how interesting the labels are. Therefore, in this study, it was aimed to determine the opinions of the visitors in a science center about the exhibits and labels and to determine the understanding of the exhibits and labels.

\section{Problem statement}

What are the conditions of science center visitors about their opinions and understandings of exhibits and labels?

For this problem; the answers to the following sub-problems were sought: Regarding the exhibits; 
1. What are the visitors' opinions about the exhibits?

2. What are the conditions of the visitors to understand what is aimed to be explained in the exhibits?

3. What are the reasons for visitors not to understand exhibits?

Regarding the labels;

4. How are the conditions of the visitors' noticing, reading and understanding the labels in the exhibits?

5. What are the reasons for visitors not to read the labels in the exhibits?

6. What are the opinions of the visitors regarding the adequacy of the labels in the exhibits?

7. What are the visitors' suggestions for the labels in the exhibits?

\section{Methodology}

In this study, qualitative research method was used. Semi-structured interview technique was used to obtain the opinions of the visitors about the exhibits and labels. Interviewing is the most practical way to learn about people's knowledge, thoughts, attitudes and behaviours on different topics and their causes (Patton, 2014).

\section{Study group}

The study group of the research consists of visitors coming to Kocaeli Science Center between the dates of October 2017-December 2018, when the researcher observed in the science center. Interviews were conducted with 95 (44 female, 51 male) who accepted the interview request.

Table 1 Demographic Characteristics of the Interviewees

\begin{tabular}{lll}
\hline Gender & Female & 44 \\
& Male & 51 \\
& Total & 95 \\
\hline Age groups & $10-15$ age & 79 \\
& $16-20$ age & 9 \\
& $21-25$ age & 3 \\
& $26-30$ age & 4 \\
\hline
\end{tabular}

As seen in Table 1, 79 of the interviewed people are between 10-15 years old, 9 are between 16-20 years old, 3 are 21-25 years old and 4 are between 26-30 years old.

\section{Data collection tools}

In order to determine the opinions of the visitors about exhibits, labels, reading the labels, understanding the exhibits and labels, an interview form was preferred as a data collection tool. For the purpose of preparing an interview form; first, a literature review was conducted on out-of-school learning and environments, informal learning, science centers (Anderson, Lucas, Ginns, 2003; Bozdoğan, 2007; Cox-Petersen, Marsh, Kisiel \& Melber, 2003; Gutwill \& Allen, 2009; Hakverdi Can, 2013). Afterwards, a draft questionnaire was prepared and a form was prepared for a semi-structured interview from the questions appropriate for the purpose of the research. Preliminary applications were carried out to measure the functionality of the questions in the interview form and changes were made in the questions in line with the answers received from the visitors. The visitors were 6 girls and 4 boys aged 10-14. Opinions were received from 2 science educators who worked in the field of out-of-school learning and science education. Necessary corrections were made and the 
missing parts were arranged. Since it was thought that the notes kept at the time of the interview would prevent fluency, recording with a voice recorder was preferred in the study. The interviews conducted in line with the permissions received from the visitors were recorded with a voice recorder and then resolved. Necessary permissions were obtained by contacting the science center officials for the implementation of the prepared data collection tool.

The order and content of the interview questions change according to the answers given by the visitors. First of all, visitors were asked about how they found the exhibits and what they wanted to explain in the exhibit. Afterwards, the questions in Figure 1 were directed to the visitors, who replied that I understood what it was aimed to be explained in the exhibits:

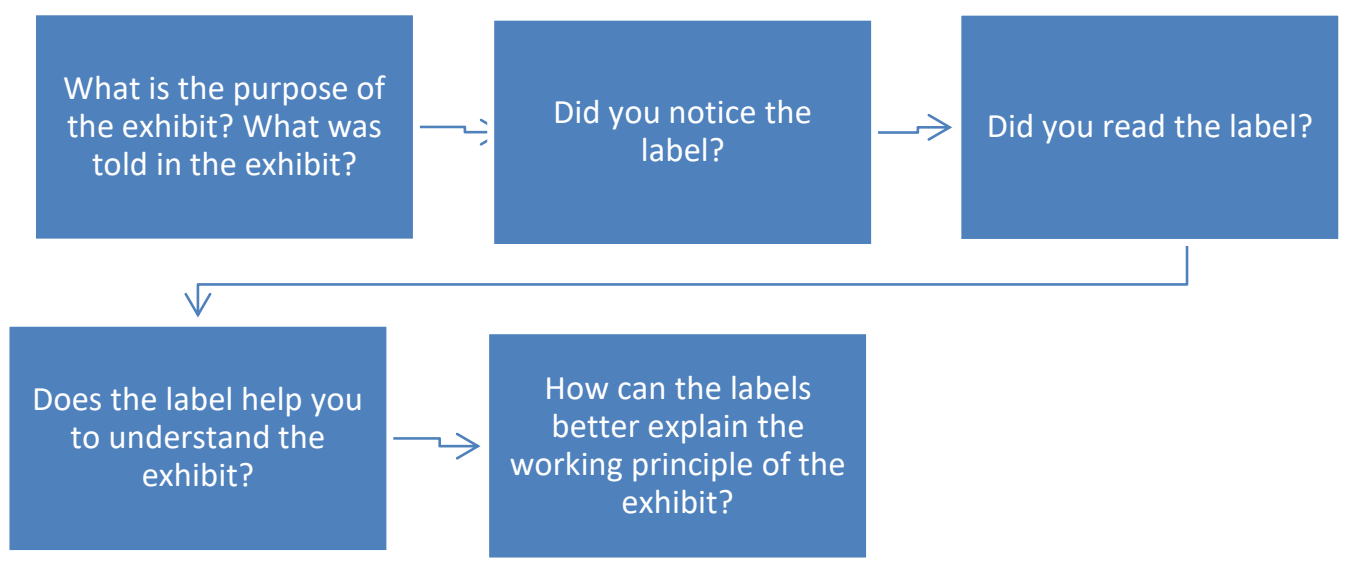

Figure 1. Questions asked to visitors who gave the answer "I understood what is aimed to be explained" in exhibits

The questions in Figure 2 were directed to the visitors, who stated that they did not understand what is aimed to be explained in the exhibit:A

Why do you

think you did

not understand

the exhibit?

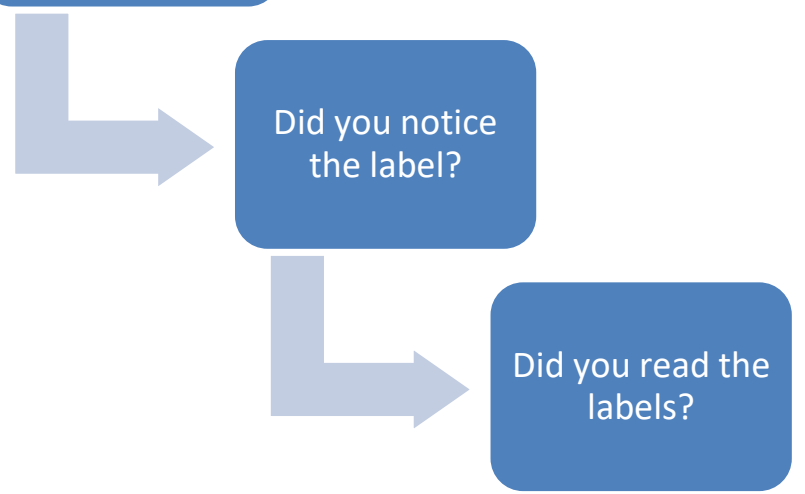

Figure 2. Questions asked to visitors who did not understand what is aimed to be explained in the exhibit 


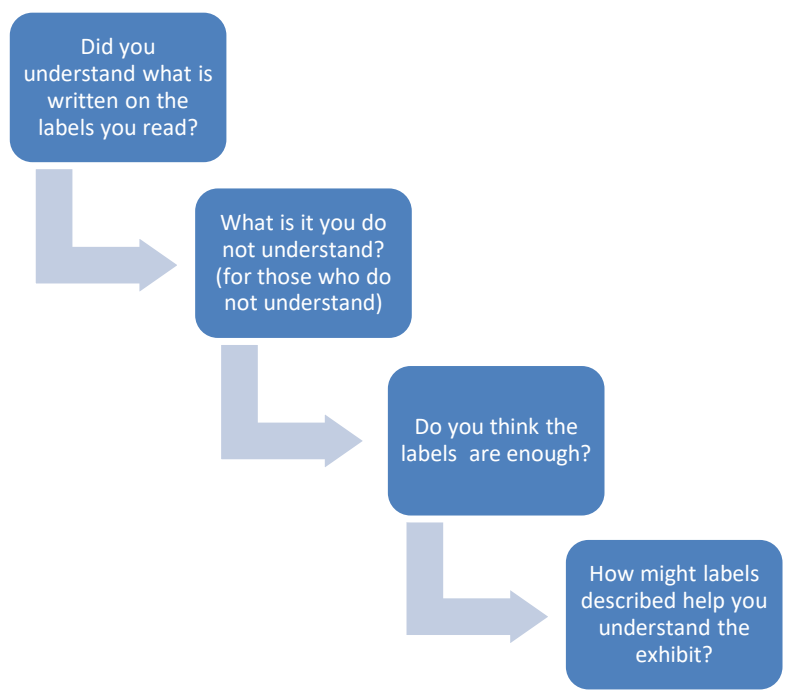

Figure 3. Questions directed to people reading the labels

For those who did not read the labels, "Why did not you read the labels?" question was posed. The final form of the interview form is given in Table 2 .

Table 2 Questions asked during interviews

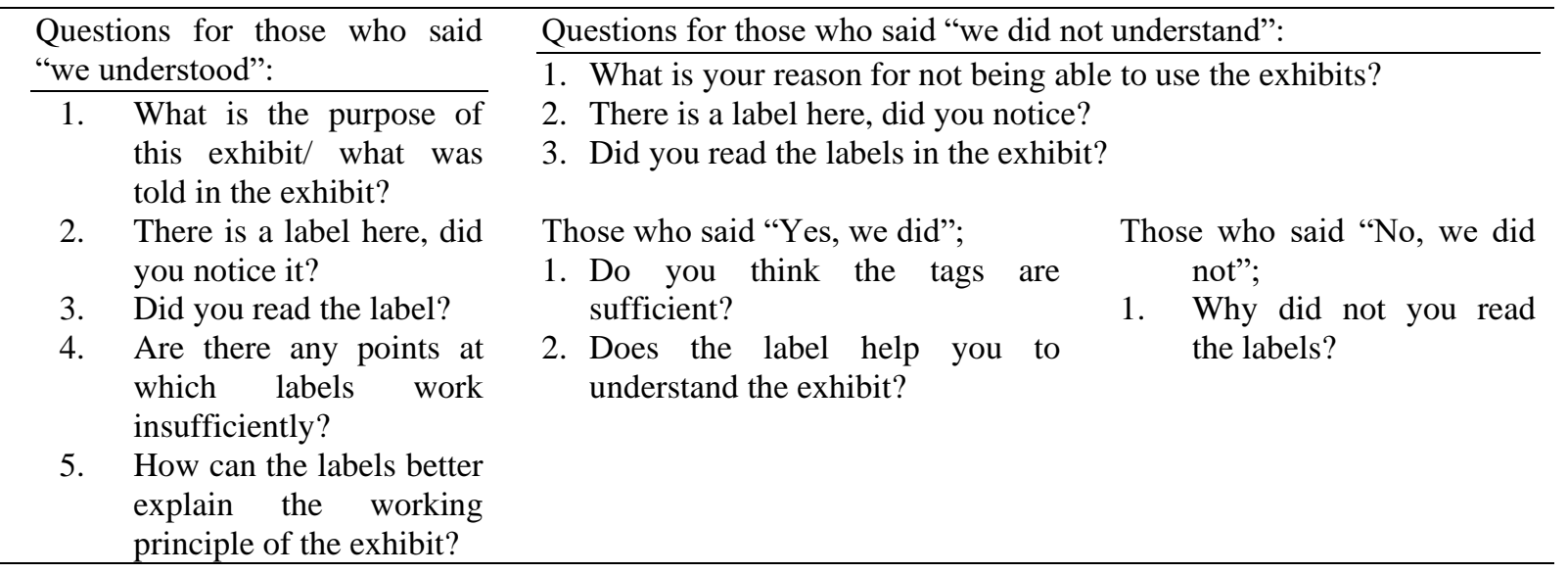

To ensure the validity of the study, 2 different associates/lecturers' opinions and participants' approvals were taken. Besides; data collection tool, data collection process and analysis process were explained. Voice recording device was used during the negotiations to ensure the reliability of the survey, thereby trying to prevent the loss of data.

\section{Environment of the research}

Research was conducted in Kocaeli Science Center, located in Kocaeli, one of the metropolitans of Turkey. Kocaeli Science Center was established in partnership with Kocaeli Metropolitan Municipality and TÜBİTAK. Kocaeli Science Center is located on an area of 8,500 square meters within the Seka Paper Factory, the foundation of which dates back to1934. Seka Paper Factory has been restored and continues to serve as Kocaeli Science Center and Seka Paper Museum. In the science center, there are four different galleries as Perception and Reality Gallery, Dynamic World Gallery, Sultans of Science Exhibit and Water Area Gallery. In the science center, there are 250 exhibits, as well as a science scene, a library, a science cafe, and an Industry 4.0 Inventor World Laboratory where scientific demonstrations and interviews are held (url1. www.kocaelibilimmerkezi.com ). 


\section{Analysis of the data}

The data obtained during the interviews to determine the opinions of the visitors about the exhibits and labels were analyzed by content analysis. The aim of content analysis is to reach the concepts and relationships that will be used to explain the data. The collected data is first conceptualized, then organized, and themes are determined accordingly. Basically, the process is to gather similar data within the framework of certain concepts and themes and to organize and interpret them in a way that the reader can understand. The analysis of qualitative research data could be given in four stages: 1) Coding the data, 2) Finding themes based on the codes, 3) Editing the codes and themes, 4) Identifying and interpreting the findings (Yıldırım \&Şimşek, 2011).

The interview data were analysed separately by two researchers and codes were created independently. Then, the researchers came together, compared the codes, made discussions, and created themes from the codes that were both ideas as a result of the evaluations. The codes created were supported by direct quotations from the statements of the participants. The statements were given directly and without comments.

The expressions of visitor opinions obtained in the study are symbolized as $1 \mathrm{~F}$ ( 1 refers to the first interviewee and $\mathrm{F}$ refers to female, that is gender), $2 \mathrm{~F}$ ( 2 refers to the second interviewee and $\mathrm{M}$ refers to male, that is gender).

The following codes were used to analyse the visitors' conditions of understanding the exhibits:

Table 3. Codes Related to the Visitors' Conditions of Understanding the Exhibits

\begin{tabular}{ll}
\hline Codes & Explanation \\
\cline { 2 - 2 } Understanding & $\begin{array}{l}\text { Scientifically complete and accurate explanation. } \\
\text { Lacking understanding }\end{array}$ \\
& $\begin{array}{l}\text { Understanding only part of what is aimed to be explained in the } \\
\text { exhibit. }\end{array}$ \\
To describe & Rather than knowledge, just telling what is done. \\
To not understand & Not understanding anything about the exhibit. \\
Uncertain $(0)$ & The expression is not meaningful \\
\hline
\end{tabular}

In order to make these codes, visitors were asked what was told at the exhibit. Understanding status was decided in line with the answers given. If the fact/principle described in the exhibit is cited correctly, it is coded as "understanding". If the answers are related to the exhibit, but there is no clear narrative, they are coded as "incomplete understanding". If the visitors only talked about what they did in the exhibit, they are coded as "to describe". If they did not have correct expressions about the exhibit, it is coded as "to not understand". If they did not make meaningful expressions, it is coded as "uncertain".

\section{Findings}

In this section, the findings obtained in the study are presented under two main titles, related to exhibits and labels.

\section{Findings about the exhibits}

Under this heading, opinions about the exhibits and data on understanding the situation to be told in the exhibits are presented. 


\subsection{Visitors' opinions on exhibits}

The questions posed to the visitors were asked after examining the exhibits they were most interested in in the galleries. These exhibits are; Video Microscope, Phases of the Moon, 3D Sandbox, Goldfish, Monochrome Room, Blind Spot, Energy from Death, Air Circles, Volcano, Seismograph, Flying Objects, Liquefaction, Water Rotator, Crooked Room, Gravity Well, Pupil, Touch to arc, Kaval (Shipherd's pipe), No Sound in Space, Molecular Vibration, Sound Spectro, Thinking Time, Capture Sound Waves, Colorful Shadow Experiments, Blood Cells in the Eye, Ear Tricks, Flow Formations, Cell Model, Sound Paths, Gas Model .

The answers of the visitors were interpreted by categorizing them within a frequency Table 4 .

Table 4. Visitors' Opinions about Exhibits

\begin{tabular}{lll}
\hline Themes & Codes & Frequency \\
\hline & Finding beautiful & 55 \\
& Liking & 11 \\
Positive & Finding impressive/surprising & 7 \\
& Finding Engaging/Unusual/Different & 6 \\
& Finding Fun/Enjoyable/Funny & 5 \\
& Finding informative & 5 \\
Negative & Finding related to course topics & 2 \\
\cline { 2 - 3 } & Not to understand & 6 \\
& Finding Boring\Bad \Dislike & 2 \\
\hline
\end{tabular}

When Table 4 is examined it is found out that; the opinions of the visitors about the exhibits were gathered under two themes: positive and negative. While the majority of the visitors gave positive opinions (91), some of them expressed negative opinions (10). Among the positive responses, the "finding beautiful" outnumbers others, which is followed by "liking" (11). On the other hand, some of the visitors stated negative opinions such as they could not understand the exhibits (6) and they could not make us of the information (2).

Examples of the visitors' positive responses to the question "How did you find the exhibit?":

In Dynamic World Gallery, 3F named person said for the "Video Microscope" exhibit "I think it is very good to examine.", 99M named person expressed for "Phases of the Moon" exhibit "I like the exhibit as it is a good thing to study the phases of the Moon.", for the "3D Sandbox" exhibit, 1F named person said "We found it beautiful, fun.", for the "Goldfish" exhibit, 17F named person said, "Well, it is also related to the topics we have covered this year. Describes how breeding occurs in animals".

As a positive comment for the "Monochrome Room" exhibit in the Perception and Reality gallery, 29M named person said "We liked it, it is very surprising, everything is getting darker except for that cow.". For the same exhibit, 59M said "I found it beautiful, it makes sense.", another visitor 49M said "Awesome exhibit is beautiful, great for taking pictures.".

The negative comments of the visitors regarding the exhibits are as follows:

A visitor, 7M, who examined the Volcano exhibit commented as "I don't like it much, it seems a bit boring to me."

The visitor named 35F, who examined the "Blind Spot" exhibit in the Perception and Reality gallery, said "I did not understand much." As a result of the observations and other interviews, it can be said that the "Blind Spot" is an exhibit that is hardly understood by the visitors. 


\subsection{Visitors' understanding conditions of exhibits}

In order to determine the visitors' understanding conditions of exhibit and the scientific knowledge included in the exhibit, "Did you understand what was explained in the exhibit?" was asked. Those who responded as "We understood", afterwards the question "What is aimed to be explained in this exhibit?" was asked. The findings are presented in Table 5:

Table 5. Findings for Visitors' understanding conditions of exhibits

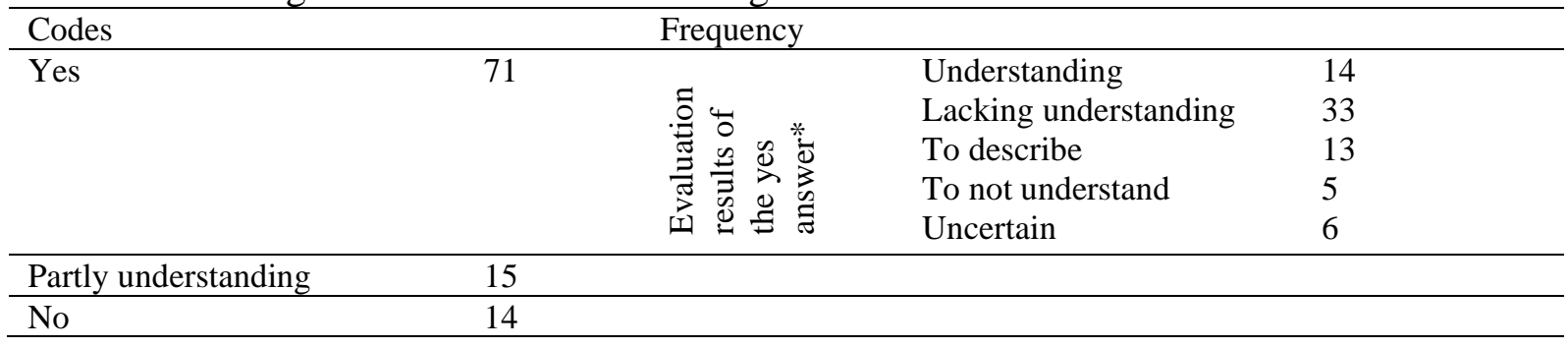

*Descriptions of the codings are given in the data analysis section.

When Table 5 is examined, 71 of the visitors stated that they understood what is aimed to be explained in the exhibit, 14 of them said they did not understand and 15 of them stated they partially understood. When the answers of 71 visitors who stated that they understood were examined, it was determined that 14 of the visitors understood, 33 of them lacked an understanding, 13 of them only described the exhibit, 5 of them did not understand what was intended to be explained in the exhibit, and 6 of them said they were uncertain. Examples of codings are presented below:

The visitor 60M, who examined the exhibit entitled "No Sound in Space" and understood what was intended to be explained in the exhibit said, "No sound in space, that is, there is no substance in the space, there will be no sound vibration because there is no air, and the other propeller does not turn because no air is able to reach the other propeller even though the other propeller turns.".

It can be said that a vast majority of the visitors articulated that they lacked an understanding of the exhibit. For example; 1F named person who examined the exhibit of "3D Sand Pool" said, "Now the highest here is red, the lowest places such as the bottom are blue. I think here about sea level, altitude and so on are explained". It is seen that the visitor does not fully understand what is intended to be explained in the exhibit.

Some of the visitors described only how to use the exhibit when asked what they understood from the exhibit. For example; The visitor, who examines the series "Single Color Room" named 70F, answered as "When this button is pressed and shed light to these, they become colorful."

A visitor examined the "Monochrome Room" exhibit about the uncertain responses of the visitors, said "Well, I think it is to take a picture." (26F).

\subsection{Reasons for visitors not to understand the exhibits}

Exhibits addressed to visitors; Blind Spot, Air Rings, Monochrome Room, Gas Model, Seismograph, Gravity Well, Touch to arc, Flow Formations, Colorful Shadows. 20 visitors who stated that they do not understand or partially understand what is intended to be explained in the exhibit, gave responses to the question "What is your reason for not understanding the exhibits?" as in Table 6. 
Table 6. Visitors' Opinions about Reasons for Not Understanding Exhibits

\begin{tabular}{ll}
\hline Codes & Frequency \\
Do not know & 7 \\
Not to understand the exhibit & 3 \\
Not to understand the label & 2 \\
Cannot read the label & 1 \\
To need a guide & 1 \\
To want to take photo & 1 \\
Cannot focus & 1 \\
Cannot associate with previous knowledge & 1 \\
No answer & 3 \\
\hline
\end{tabular}

When Table 6 is examined; the opinions of the visitors about the reasons for not being able to understand the exhibits are given in 9 different codes. 7 of the visitors stated that they did not know why they did not understand the exhibits, 3 of them did not understand the exhibit and 2 of them did not understand the label. There are visitors who cannot read the label, need a guide, come to take photos, cannot focus and cannot associate with their previous knowledge. 3 of the visitors did not answer the question.

Examples of the visitors' answers are presented below:

The visitor who examined the "Blind Spot" exhibit, with the code of not to understand the label said, "I did not quite understand the script on the plate." (35F).

The visitor who examined the "Air Circles" exhibit with the code of cannot read the label said, "Because I could not read the label." (5M).

The visitor who examined the "Blind Spot" exhibit with inability to focus code said "I think it was because I myself was not able to focus on it." (61F)

The person named 49M who examined the "Monochrome Room" exhibit said, "We came to take photos." This exhibit is one of the most visited by visitors, but it is poorly understood and most photographed exhibit.

The visitor who examined the "Gas Model" exhibit with the code of inability to associate with previous knowledge said "So, it wasn't familiar, I don't know."(103M)

\section{Findings about the labels in the exhibits}

In this section, the conditions of visitors to notice, read and understand the labels, reasons for not reading the labels, and their views on the labels are given:

\subsection{Visitors' conditions of noticing and reading of labels}

To the visitors "There is a label here, did you notice?" and "Did you read the label?" questions were asked. The findings are given in Table 7.

Table 7. Visitors' Conditions of Noticing and Reading of Labels

\begin{tabular}{lll}
\hline Findings on labels & & Frequency \\
\hline Noticing the label & Yes & 78 \\
& No & 17 \\
Reading the label & Yes & 41 \\
& No & 32 \\
& A little & 8 \\
\hline
\end{tabular}

As seen in Table 7, the majority of visitors (78) noticed the labels. 41 of them stated that they read the label, 32 of them did not read and 8 of them read a little. 


\subsection{Reasons for visitors not to read labels in exhibits}

To 32 visitors who said they did not read the labels "Why did not you read the labels?" question was asked. The findings are presented in Table 8:

Table 8. Reasons for Visitors Not Reading The Labels In The Exhibit

\begin{tabular}{lll}
\hline Themes & Codes & Frequency \\
\hline & Want to try it first & 12 \\
Doing it without reading & Thinking he/she can do it without reading & 1 \\
& Easy-to use of the exhibit & 1 \\
& Read it later & 1 \\
& Not wanting to read & 3 \\
\cline { 2 - 3 } Not interested in label & There was no time & 1 \\
& It was not interesting & 1 \\
Know beforehand & Know it beforehand & 1 \\
& To feel lazy & 1 \\
\cline { 2 - 3 } I did not see it & Learning from his/her friend & 1 \\
We took photos & The teacher has taught it before & 5 \\
\cline { 2 - 3 } I do not know & & 2 \\
\hline
\end{tabular}

When Table 8 is examined, the reasons why visitors did not read the labels are examined under 6 themes. Looking at the codes under the doing it without reading the label theme; 12 visitors stated that they wanted to try the exhibit first, 1 visitor thought they could do without reading the label, 1 visitor found the exhibit easy, and 1 visitor would read the label after using the exhibit. Looking at the codes under the theme of not interested in the label; 3 visitors stated that they did not want to read, 1 visitor did not have time to read, 1 visitor stated that the label was not interesting. In the codes of those who knew it before, there were visitors stating that he/she did not read the label because he/she knew the exhibit beforehand, because he/she learned it from his/her friend and because he/she was told by the teacher beforehand. There were 3 visitors who stated that they did not read the label because they did not see the label, and 1 visitor who stated that he/she did not read it because he/she took photos. On the other hand, 2 visitors did not express their opinions by saying I do not know.

Visitors' preferences for examining exhibits may change, while some visitors prefer to practice and then read the label; conversely, some read and then practice. 13F named person said, "I will read in an order, I am already looking at the exhibit and then reading the label to understand why.", 8M: "I looked at the exhibit first, and then I read it.", The visitor named 96M, who examined the Audio Paths exhibit, "So we wanted to examine directly, and I wanted to look directly." he said.

The visitor named 99F, who examined the "Phases of the Moon" exhibit, said, "I notice that the phases of the Moon have changed when I rotate the exhibit. Namely, sometimes its dark face is over there, so the Moon shows how it looks from Earth as it changes position, actually this is for me.". He did not notice the label, but when he looked at the exhibit, he stated that he could easily understand without reading, since it was clear what was intended to be explained.

The visitor who examined the "Video Microscope" exhibit said about the code to use the exhibit immediately, "I would actually read it but when I came here, I did not know, I looked directly at it." (2M).

The person named 4F who examined the "energy from death" exhibit said "It already had a step, I thought we could do it by selecting an animal here and turn it easily". In this exhibit, 
visitors can see the stages of the animal after death by selecting an animal type from the screen in the exhibit and turning the button below. Since the implementation phase of the exhibit is not complex, visitors do not need to read the label, finding the use of the exhibit simple.

Regarding to know beforehand, the $25 \mathrm{~F}$ visitor said, "I had read in our first entrance, which was visiting everywhere in the last half hour, so I didn't need to read.".

A visitor examining the "Monochrome Room" exhibit with There was no time code: "Because the teacher called us, we did not have time." (85M) said.

Some of the visitors do not need to read the labels while examining the exhibits related to the subjects in the school curriculum. For an exhibit where the mixture of colours is shared, the person named $23 \mathrm{~F}$ said, "Because our teacher had told us about this before, and I remembered it when I first saw it, I did not need to read it.".

When some visitors find the exhibits interesting, they prefer to take pictures rather than dealing with the labels. The person named 29M found the "Monochrome Room" exhibit surprising, noticed the label but did not read it. As a reason for not reading the label "Because we took a photo." he said. The visitor who examined the "Monochrome Room" exhibit with the code I came to take photo said "Here we came to take photos." (49M).

Others did not see the labels as they preferred to use the exhibit directly. For example; The person named 10M examined the "Air Circles" exhibit and said "I did not see it, so I dived directly.", 103M visitor who examined the Gas Model exhibit said "I did not see, I came from that way."

Some visitors did not want to read the labels and commented as following: For the "Air Circles" exhibit, 5M: "I didn't see it at first, because I felt lazy to read it later." , 81F for the "Blood Cells in the Eye" exhibit: "I did it myself because I didn't want to read it.", for the "Cell Model" 94M: "Obviously it was not interesting.", for the "Pupil" exhibit 110M: "I don't know, when my friends did it, I came closer and looked at it for a moment., suddenly light came out."

\subsection{Visitors' opinions on the adequacy of the labels}

In order to collect data on this subproblem, both visitors who understand and do not understand the exhibits are asked "Are the labels enough?" question. The findings obtained from 11 visitors stating that they do not understand what is intended to be explained in the exhibit and read the label are given in Table 9.

Table 9. Visitors' Opinions on Sufficiency of Labels

\begin{tabular}{ll}
\hline Codes & Frequency \\
\hline No & 6 \\
Yes & 3 \\
A little & 2 \\
\hline
\end{tabular}

When Table 9 is examined; 6 visitors found the labels insufficient, 3 people found sufficient and 2 people found a little sufficient.

A visitor who found the label sufficient was 55F who said for the "Blind Spot" exhibit: "So it may be enough but it is not enough for some who do not understand." , a visitor who found the label insufficient was $33 \mathrm{~F}$ who said for the "Touch to arc" exhibit: "I think it's not enough.", 40F for the "Blind Spot" exhibit conveyed: "Well, that means not enough, we 
couldn't do it.", the visitor who found the label a little sufficient for the "Gravity Well" exhibit 47M: "A little bit.".

The answers of the 26 visitors who stated that they understood what was aimed to be explained and read the label, while answering the question "Are there any points where the label is insufficient?" are given in Table 10.

Table 10. Visitor Opinions Regarding Insufficiency of the Label

\begin{tabular}{ll}
\hline Codes & Frequency \\
\hline No & 21 \\
Superficial expression & 5 \\
\hline
\end{tabular}

When Table 10 is examined, 21 people found the labels sufficient, and 5 visitors stated that the expression of the labels was superficial.

A visitor (12M) who examined the "Liquefaction" exhibit said about the superficial expression of the labels: "For example, there could be more detailed information on what's going on. It was expressed superficially".

A visitor (14M) examined the "Video Microscope" exhibit on sufficiency of the labels said: "I think it is appropriate for our age.".

The answers of the visitors stating that they understood what is aimed to be shared in the exhibit, to the question "Did the labels affect your understanding of the exhibit?" are given in Table 11.

Table 11. Visitor Opinions on the Effect of Labels on Understanding the Exhibit

\begin{tabular}{ll}
\hline Codes & Frequency \\
\hline Yes & 33 \\
No & 2 \\
A little & 2 \\
\hline
\end{tabular}

When Table 11 is examined, 33 visitors stated that labels were effective in understanding exhibits, 2 visitors stated that they were somewhat effective, and 2 visitors said they were not.

Direct quotations from visitor opinions on the effect of labels on understanding the exhibit are below:

The visitor examined the "Monochrome Room" exhibit said: "Yes, it was not clear when we first entered, but it was obvious what it wanted to tell after reading it." (46M).

The visitor who examined the "Gas Model" exhibit shared: "I don't understand much." $(111 \mathrm{~F})$.

\subsection{Visitors' suggestions on labels}

In order to collect data on this sub-problem, visitors who both understood and did not understand the exhibits were asked about their recommendations for labels. The answers given by the visitors are given in Table 12 .

Table 12. Suggestions of Visitors to Make Labels More Comprehensible

\begin{tabular}{ll} 
Codes & Frequency \\
That condition is sufficient & 10 \\
It would be better explain with a visual & 9 \\
More information / explanation can be included & 9 \\
Application steps can be explained directly instead of writing them one by one. & 3 \\
Can be a tablet. & 3 \\
\hline
\end{tabular}


$\begin{array}{lr}\text { It can be more colourful and remarkable. } & 2 \\ \text { The fonts can be larger. } & 2 \\ \text { Scientific information could be explained by a video. } & 2 \\ \text { Different pieces must be added to the exhibit for application. } & 1 \\ \text { It can be a drawing. For example, it can be explained by drawing. } & 1 \\ \text { No } & 3\end{array}$

When Table 12 is examined, 10 visitors stated that the labels were fine and 10 visitors had no idea. Regarding the form of the label, 9 visitors expressed their opinions on adding visuals to the labels and 9 visitors detailing the labels. 2 visitors stated that labels were more colourful, more remarkable and larger in fonts. In order to support the narration of the label, 3 visitors suggested adding tablets, 2 visitors suggested adding videos, 1 visitor gave examples of voice commands.

Some visitors stated that, although they understood the purpose of the exhibit, more samples were needed on the labels. A visitor who examined the "Video Microscope" exhibit said "For instance, examples could be given." (3F).

Visitors' opinions on how labels can be better are as below:

A visitor (9M) who examined the "Flying Objects" exhibit said "For example, it could say something like 'put another heavy ball and try it'."

A visitor (12M) who examined the "Liquefaction" exhibit said "During the study we would like it to explain even more events, when we run this exhibit.".

A visitor (26F) who examined the "Monochrome Room" exhibit said "It could have been coloured a little more, it could have been more distinctive.".

A visitor (30F) who examined the "Air Circles" exhibit said "Or maybe it can be a little bigger to attract people's attention, I don't think of anything other than this".

A visitor (33F) who examined the "Touch to Arc" exhibit said "If someone waits there as an officer, we can understand it better. There could be something next to the label or something like a tablet and show us what it is. ".

A visitor (82F) who examined the "Colorful Shadows" exhibit said "They can write bigger, in fact, they can make it more fun.".

A visitor (43K) who examined the "Touch to Arc" exhibit said "For example, if this exhibit had a small screen on one side that was left empty and it described it in such a written way and video. I think it would be easier to understand if it was that kind of thing. ".

A visitor (43F) who examined the "Gravity Well" exhibit said "Voice command.".

A visitor $(18 \mathrm{~F})$ who examined the "Gravity Well" exhibit said "I think it is good but maybe it can be explained with visuals.".

A visitor (37F) who examined the "Monochrome Room" exhibit said "So I think it's fine as it is.".

Visitor suggestions regarding the form of the label; it is more colorful, remarkable, easier, and bigger fonts. Some of the visitors stated that the narration of the label should be supported with visual elements. Some visitors found the labels well as they were, some did not express an opinion. 


\section{Conclusion and Discussion}

In this study, it was aimed to determine the opinions of visitors about the exhibits in the science center, their conditions of noticing, reading, understanding of labels, and their evaluation regarding labels.

In the interviews, it was determined that most of the visitors liked the exhibits and found them interesting. Falk and Gillespie (2009) stated that science centers and other informal environments are found fun, exciting and enjoyable by visitors. It was determined that the visitors, who stated that they did not like the exhibits or found it boring, mostly could not understand the exhibits and could not use the exhibit. In the study of Hakverdi-Can (2013), it was observed that the students found the exhibits fun but did not like the exhibits they could not understand.

Most of the visitors stated that they understood what was aimed to be explained in the exhibit. However, when asked what they understood, it was determined that most of them could not give the expected answer, made incorrect explanations, described how the exhibit worked or their observations. In many studies, it was found that learning at the science level did not occur at the expected level (Cox-Petersen, et all, 2003; Gutwill \& Allen, 2009; Hakverdi Can, 2013, Yaşar \& Gürel, 2016). The visitors, who stated that they did not understand the exhibit, stated reasons such as not understanding what was meant to be explained in the exhibit, not understanding what was written on the label, needing guidance, not being able to concentrate, and not associating with the previous knowledge.

It was seen that visitors mostly noticed and read the labels. In the study of McManus (1990), it was also determined that the majority of the visitors read the labels. In his research, Caulton (1998) stated that people are more likely to read the labels in the first part of their visit, namely before they get tired. Most of the visitors who read the labels stated that they understood the information on the label, a few of them did not understand it. It was determined that visitors who stated that they did not understand the labels, did not understand the application stages of the exhibits. In his study, Falk (1997) found that labels increase understanding of the exhibit. In this study, some of the visitors who read the label stated that the text on the label helped them understand what was aimed to be explained in the exhibit. Caulton (1998) points out that labels play an important role in visitors' use of exhibits, that the text of the label should clearly indicate the learning activity, otherwise the entertainment dimension of the exhibits will precede the learning dimension.

When asked why visitors did not read the labels, it was figured out that they wanted to practice without reading the label or wanted to use the exhibit first. Some visitors stated that they thought they could use the exhibit without reading the label, found the exhibit easy, or they would read the label after using the exhibit. Depending on the structure of the exhibit and the subject it is related to, in some exhibits, visitors can reach the correct results without reading the labels. This is thought to eliminate the need to read the label. Caulton (1998) stated that most of the visitors, in articular children, first interact with the exhibits, but read the label if they fail. Screven (1992) emphasized that visitors read if they think the labels will help them understand the exhibit. Gilbert \& Stocklmayer (2001) stated that visitors' participation in the exhibit may affect the aesthetic appeal of the exhibit, curiosity towards it and some social factors (what others do). Falk \& Dierking (2016) stated that some visitors learn better by touching and others by reading. Bitgood (2000) states that when they have a choice, visitors prefer to examine exhibits rather than reading.

Some of the visitors who did not read the labels stated that they did not want to read, that their time was not enough or that it was not interesting. Others said they had the information on the 
labels before, learned it from friends, or did not read the labels because the teachers told about them before the visit. Some visitors stated that they did not see the label. Others did not read the labels because they took photos. It was determined that the visitors who did not read the labels used the buttons, keys, arms, pistons in the exhibit, took photos, tried to learn from what they saw from their friends' doing or did not interact. On the other hand, in the observation data of McManus (1990), some of the visitors seemed not to read the labels, but when the speeches of the visitors were analyzed, he noted that sections of the information and paragraphs contained in the labels are included.

Most of the visitors stated that they found the labels sufficient and some stated that they were superficial. Visitors stated that the labels could be more colorful, noticeable and suggested that they be written more clearly and with large fonts. Some of the visitors stated that the labels can be supported with visual items, tablets, photograph, videos. Screven (1992), in his review of labels, mentioned that labels should have positive features such as requiring minimum time, being shareable, easy to see, easy to read, not being too long and not containing abstract information. Bitgood (2000) emphasizes that visitors often want to know what to pay attention to, how to focus their attention, and labels should serve for these. Falk (1997) found that when labels clearly show conceptual information, people learn more and spend more time in exhibits.

In this study, it was seen that visitors liked the exhibits in the science center. It was determined that the disliked exhibits were mostly disliked because they were not understood. Labels are an important factor in understanding the exhibits and it has been determined that they are mostly read. It is necessary and important for visitors to interact with the exhibits, make observations and give meaning to their observations in order for the teaching side of visits to science centers, which are both entertaining and educational environments, to become more effective. Labels emerge as an important factor at this point. Visitors notice and often read the labels. Therefore, it is important to organize the labels in a way that is appealing to all ages and understandable.

\section{Suggestions}

In this study, visitor opinions were taken. Visitors behaviours while examining the exhibits, the way they examine the exhibits, their comments on the exhibits, and their conversations with friends can be studied. In this study, a meeting was held after the exhibit, which was attended by the visitors to the science center the most. In subsequent studies, most frequently and least preferred exhibits can be determined and observed and visitor behaviours, conditions of their reading and understanding the label can be investigated.

\section{Acknowledgement}

- We thank to Kocaeli Science Center for their support.

- This study has been produced from the second author's master's thesis named "Examining the interaction of science center visitors with exhibits: An example of Kocaeli Science Center".

\section{References}

Allen, S. (2004). Designs for learning: Studying science museum exhibits that do more than entertain. Science Education, 88(1), 17-33.

Anderson, D., Lucas, K. B., Ginns, I. S. (2003). Theoritacal perspectives on learning in a informal setting. Journal of Research in Science Teaching, 40:177-199. 
Bitgood, S. (2000). The role of attention in designing effective interpretive labels. Journal of Interpretation Research, 5(2), 31-45.

Bozdoğan, A. E, (2007). Students interests towards science fields about exhibitions in science centers Feza Gursey Science Center in Turkey. Natural Science Education, 2(19), 517.

Caulton, T. (1998). Hands-On Exhibits: Managing Interactive Museums And Science Centres. New York: Routledge.

Cox-Petersen, A. M., Marsh, D. D., Kisiel, J. \& Melber, L. M. (2003). Investigation of guided school tours, student learning, and science reform recommendations at a museum of natural history. Journal of Research in Science Teaching, 40(2), 200-218.

Eshach, H. (2007). Bridging in-school and out-of-school learning: formal, non-formal, and informal education. Journal of Science Education and Technology, 16(2), 171-190.

Falk, J. H. \& Dierking, L. D. (1997). School field trips: assessing their long-term impact. Curator: The Museum Journal, 40(3), 211-218.

Falk, J. H. \& Dierking, L. D. (2016). The Museum Experience Revisited. New York: Routledge.

Falk, J. H. \& Gillespie, K. L. (2009). Investigating the role of emotion in science center visitor learning. Visitor Studies, 12(2), 112-132.

Falk, J. H. (1997). Testing a museum exhibit design assumption: effect of explicit labeling of exhibit clusters on visitor concept development. Science Education, 81(6), 679-687.

Gilbert, J. K. \& Stocklmayer, S. (2001). The design of interactive exhibits to promote the making of meaning. Museum Management and Curatorship, 19(1), 41-50.

Guisasola, J., Morentin, M. \& Zuza, K. (2005). School visits to science museums and learning sciences: A complex relationship. Physics Education, 40(6), 544.

Gutwill, J. P. \& Allen, S. (2009). Facilitating family group inquiry at science museum exhibits. Science Education, 94(4), 710-742.

Hakverdi-Can, M. (2013). İlköğretim öğrencilerinin bilim merkezindeki deney setleri hakkındaki görüşleri ve öğrenme [Views of Primary School Students' on Exhibits at the Science Center and Learning]. Hacettepe Üniversitesi Ĕgitim Fakültesi Dergisi, Özel Sayı (1), 219-229.

Hohenstein, J. \& Tran, L. U. (2007). Use of questions in exhibit labels to generate explanatory conversation among science museum visitors. International Journal of Science Education, 29(12), 1557-1580.

McManus, P. M. (1990). Watch your language! People do read labels. ILVS Review, 1, 2.

Patton, M. Q. (2014). Nitel Araştirma ve Değerlendirme Yöntemleri [Qualitative Research and Evaluation Methods]. M. Bütün ve S. B. Demir (Çev. Ed.). Ankara: Pegem Akademi.

Ramey-Gassert, L. (1997). Learning science beyond the classroom. The Elementary School Journal, 97(4).

Rennie, L. J. \& Williams, G. F. (2006). Adults' learning about science in free-choice settings. International Journal of Science Education, 28(8), 871-893.

Screven (1992). Motivating visitors to read labels. ILVS Review, 2(2), 183-221.

Wellington, J. (1990). Formal and informal learning in science: The role of the interactive science centres. Physics Education, 25(5), 247.

Yaşar, E. \& Gürel, C. (2016). Science Museum Exhibits' Summative Evaluation with Knowledge Hierarchy Method. European Journal of Physics Education, 7(1), 13097202. 